\title{
"Keep It Going if You Can": HIV Service Provision for Priority Populations During the COVID-19 Pandemic in Seattle, WA
}

\author{
Kristin Beima-Sofie $^{1} \cdot$ Katrina F. Ortblad $^{1,2} \cdot$ Fred Swanson $^{3} \cdot$ Susan M. Graham ${ }^{1,4}$. Joanne D. Stekler ${ }^{1,4}$. \\ Jane M. Simoni ${ }^{1,5}$
}

Published online: 8 May 2020

○) Springer Science+Business Media, LLC, part of Springer Nature 2020

On January 21, 2020, the first known case of COVID-19 in the United States was reported in Western Washington, and in late February, 2020, Seattle became the first major city in the United States reporting deaths from COVID-19 [1]. Lacking federal guidelines or examples from other USbased cities, Washington State and Seattle leadership faced the challenge of determining how to respond to COVID-19. From the beginning, it was clear that COVID-19, like many other infectious diseases [2, 3], was likely to disproportionately impact many vulnerable and marginalized populations, including racial and ethnic minorities, immigrants, persons experiencing homelessness, sexual minorities, and persons who inject drugs. These populations, which we will refer to as "priority" populations, bear the double burden of also being most vulnerable to and affected by the HIV epidemic [4].

A number of programs in Seattle dedicated to HIV prevention and care, including the Maximum Assistance (Max) Clinic, Safe.Healthy.Empowered. (S.H.E.) Clinic, and Gay City, worked to find ways to reach and provide continuous services to priority populations living with or at risk for HIV infection. The Max Clinic provides services for people living with HIV (PLWH) who have not engaged in conventionally organized HIV care, most of whom are experiencing

Katrina F. Ortblad

katort@uw.edu

1 Department of Global Health, University of Washington, Seattle, USA

2 Department of Global Health, International Clinical Research Center, University of Washington, 908 Jefferson St, 12th Floor, Seattle, WA 98104, USA

3 Gay City: Seattle's LGBTQ Center, Seattle, USA

4 Department of Medicine, University of Washington, Seattle, USA

5 Department of Psychology, University of Washington, Seattle, USA challenging life circumstances including homelessness, substance use, incarceration, and untreated mental health needs $[5,6]$. The S.H.E. Clinic provides comprehensive care to women experiencing homelessness who are engaged in survival sex and either have or are at risk of HIV infection. Gay City is a lesbian, gay, bisexual, transgender, and questioning (LGBTQ) center that promotes wellness in sexual and gender minority communities by promoting health services, including HIV testing and counseling, PrEP and access to helpful resources [7-9]. To provide effective HIV prevention and care to priority populations, these programs have learned that HIV service delivery must be flexible, familiar, and paired with needed social interventions. For example, the Max and S.H.E. Clinics offer walk-in appointments and provide food and transportation vouchers to patients [5, 6], while Gay City offers walk-in HIV testing and counseling by staff representing the communities the program serves [7].

When COVID-19 emerged in Seattle [1], these programs, like other health service programs, rapidly adapted their operations to decrease client visits to maintain the safety of clients, staff, and the greater Seattle community, while maintaining the delivery of essential services. An examination of how the MAX Clinic, S.H.E Clinic and Gay City have adapted the provision of HIV prevention and care services to priority populations may assist other cities at risk of or in early stages of the COVID-19 pandemic. Insights from leaders of these clinics revealed challenges and recommendations in the following key areas: program operations, counseling services, testing services, pharmacy services, and other essential services (see Table 1).

\section{Program Operations}

As the COVID-19 pandemic continues, programs providing HIV services have had to implement evolving recommendations and make difficult—and often uncertain—decisions 
Table 1 Challenges and recommendations for HIV service delivery to priority populations in Seattle, WA during COVID-19

\begin{tabular}{|c|c|c|}
\hline & Challenges & Recommendations \\
\hline Program operations & $\begin{array}{l}\text { - Need to reduce clinic flow and prevent spread of } \\
\text { COVID-19 } \\
\text { - Avoidance of hospital visits (i.e., emergency room } \\
\text { visits) for non-emergency care } \\
\text { - Ensurance of continued access to a friendly, safe, and } \\
\text { comfortable care environment }\end{array}$ & $\begin{array}{l}\text { - Identify stable clients/patients eligible for telemedicine/ } \\
\text { phone visits } \\
\text { - Increase outreach support, while maintaining in-person } \\
\text { visits for those where telemedicine is not feasible or } \\
\text { advisable } \\
\text { - Maintain safety of peers providing HIV service provision }\end{array}$ \\
\hline Counseling services & $\begin{array}{l}\text { - Lack of client/patient access to phone/internet (tel- } \\
\text { emedicine) } \\
\text { - Loss of personal connection with clients/patients } \\
\text { - Shorted counseling sessions } \\
\text { - Encouraged social distancing (including sex) } \\
\text { - Increased fear and anxiety }\end{array}$ & $\begin{array}{l}\text { - Provide counseling services via telemedicine or phone } \\
\text { when possible } \\
\text { - Maintain counseling from community members when } \\
\text { possible } \\
\text { - Link clients/patients to online support groups } \\
\text { - Avoid finger-wagging of HIV risk-related behaviors dur- } \\
\text { ing social distancing measures }\end{array}$ \\
\hline Testing services & $\begin{array}{l}\text { - Blood samples must be collected in person } \\
\text { - Frequent testing required for routine medical care (e.g., } \\
\text { drug refills, disease screening) }\end{array}$ & $\begin{array}{l}\text { - Use phone screening prior to in-person testing (for } \\
\text { COVID-19 \& STI symptoms) } \\
\text { - Consider the feasibility of social distancing at testing } \\
\text { locations } \\
\text { - Enable flexibility in testing requirements for drug refills } \\
\text { and non-urgent medical conditions }\end{array}$ \\
\hline Pharmacy services & $\begin{array}{l}\text { - HIV medications only dispensed for } 30 \text { days } \\
\text { - Drug dispensing and prescribing requires laboratory } \\
\text { tests }\end{array}$ & $\begin{array}{l}\text { - Tailor pharmacy services to individuals' risk and medical } \\
\text { urgency (e.g., longer drug dispensing, wave testing for } \\
\text { drug refills) }\end{array}$ \\
\hline Other essential services & $\begin{array}{l}\text { - Private and consistent housing needed for prolonged } \\
\text { social distancing } \\
\text { - Maintenance of services clients/patients rely on (e.g., } \\
\text { food \& transportation vouchers) } \\
\text { - Substance use/addiction }\end{array}$ & $\begin{array}{l}\text { - Maintain provision of essential social services } \\
\text { - Prioritize access to safe private spaces for social isolation } \\
\text { - Relax restrictions on allowable activities }\end{array}$ \\
\hline
\end{tabular}

about whether and which services qualify as "essential". While Gay City has a long-standing telePrEP component [8], other programs have had to quickly convert many services traditionally provided in person to telemedicine or telephone modalities. Converting some services to telemedicine may have a significant negative impact on the priority populations severed by the Seattle programs. A recent analysis of Max patient values identified that positive interactions with program staff — sometimes considered by patients to be like family - and the provision of care in real time (via walk-in visits) were critical components of the Max program that allowed patients to successfully engage in HIV care [10]. The strong push to convert patient visits from in-person to telemedicine during COVID-19 could undermine strategies used by these programs to reach priority populations and retain them in care [6]. Shifting family-like clinic service provision to one in which connections are strained by digital or telephone technology might also lead to broken trust and trigger feelings of abandonment among patients served by these programs.

Maintaining program operating hours and coordinating with nurses at supportive housing locations (for the provision of services such as COVID-19 screening) might help priority populations avoid seeking HIV-related services in emergency rooms (increasing the potential for COVID-19 exposure and competing for healthcare resources). One caveat in terms of continuing face-to-face service is, of course, the risk for program staff on the front lines. This is especially important to consider in programs in which many volunteers and sometimes staff members are peers or paraprofessionals (e.g., Gay City). These individuals may not have the benefit of training and experience in infection control. Moreover, they may have health concerns of their own, including compromised immune systems. Maintainenance of care for priority patients should never place their peers in service positions at undue risk.

\section{Counseling Services}

In some locales, fear and anxiety surrounding COVID-19 has subsumed concerns about HIV acquisition and shifted health provider discussions away from reducing HIV transmission risk. However, for some persons at high risk of HIV acquisition, risk behaviors may not have changed significantly, or may have increased, during COVID-19 social distancing for a variety of reasons including mental health needs, substance use, and sex work or survival sex. Maintenance of counseling options around sexual behavior and PrEP adherence, including sex-positive messaging 
describing alternatives to maintain sexual health (e.g., video chats or phone sex), remain critical for HIV prevention during social distancing. For PLWH, counseling can be vital to address mental health needs and substance use and avoid medication interruptions.

Unlike some essential services, counseling can sometimes be delivered in a telemedicine format, with appropriate allowances for privacy and data safety [11]. However, the challenges of telemedicine are compounded in priority populations without reliable access to high-speed internet and telephones. An additional challenge of counseling using telemedicine is the loss of the personal connection, which often results in shortened counseling sessions. Linking clients to online support groups and reaching out more frequently can help ensure clients receive comprehensive counseling support.

\section{Testing Services}

The Max Clinic, S.H.E. Clinic and Gay City have all confirmed new HIV infections and several sexually transmitted infections (STI) since social distancing recommendations came into effect in Seattle on March 23, 2020. To keep HIV and STI services available to clients in need, while maintaining the safety of clients and staff, these programs have implemented a number of new testing strategies. These include phone screening clients for COVID-19 symptoms before they come to testing locations, syndromic management of STI symptoms by phone, and home-based self-testing for HIV and STIs under supervision of program staff. Other strategies include minimizing hours of operation at particular testing locations where social distancing practices are difficult to achieve (e.g., bathhouses) or avoiding testing at these locations all together. Additionally, programs have found ways to reduce the overall testing burden by waving HIV and STI testing for stable clients seeking PrEP refilling and holding screening for non-urgent medical conditions (e.g., cancer). Holding testing or screening for non-urgent medical conditions, however, is likely to negatively impact PLWH who disproportionately experience co-morbid infections [12].

\section{Pharmacy Services}

Maintaining a supply of medications for both HIV treatment and prevention is a priority. In Washington State, policy has changed to support 90-day supplies of medication instead of the typical 30-day supply to meet the demand and obviate the need for additional pharmacy visits. During COVID19 , flexibility in medication service delivery is paramount, with relaxed timeframes for required labs before prescribing and dispensing (described above). Although current CDC guidelines recommend prescribing no more than 90 days of PrEP [13], even prior to COVID-19, there was discussion about whether recommended PrEP monitoring is excessive and whether some PrEP clients can have longer intervals between testing, particularly for long-standing clients who report excellent PrEP adherence.

\section{Other Essential Services}

In addition to HIV services, the Max Clinic, S.H.E. Clinic and Gay City provide access to other essential services for priority populations, including food, housing and safe social spaces. It is important that social distancing policies take into account the unique needs of priority populations, ensuring that access to services these individuals need continues despite COVID-19. A surprising positive development in response to COVID-19 in Washington State has been increased access to temporary housing for many individuals experiencing homelessness and living with HIV [14]. The COVID-19 pandemic has increased political will and resources to provide people with access to private spaces, with available water and soap, bathrooms and kitchens. To ensure those in temporary housing remain housed, Seattle programs have afforded flexibility in housing requirements, including relaxing restrictions on who can visit and providing on-site access to needed services, including methadone treatment.

\section{Discussion}

As the first US county to achieve the UNAIDS' HIV 90-9090 targets, Seattle/King County was well positioned to set the example in HIV prevention and treatment service delivery when it experienced COVID-19. Priority populations rely on access to safe, friendly and supportive services. During this pandemic, as well as any other future socially disrupting events, it is important to recognize that adaptations in service delivery that are acceptable solutions for some populations may further harm already disadvantaged populations. Seattle programs have ensured that adapted HIV services are providing continued access to non-stigmatizing care for priority populations from trusted service programs during COVID-19. Understanding the needs of priority populations, and tailoring HIV and other health services to meet their needs, can minimize long-term health impacts and help reduce health disparities.

Acknowledgements We would like to acknowledge all the clinicians and nurses at the Max Clinic and S.H.E. Clinic, the HIV counselors at Gay City who are providing essential services despite limited clinical 
training, and the other staff at these programs. In particular we would like to acknowledge Dr. Julie Dombrowski, who share with us her experiences working at the Max Clinic, and Dr. Shireesha Dhanireddy, who shared with us her experiences working at the S.H.E. Clinic. The authors of this paper received no direct funding for this publication. KFO was supported in part from the National Institute for Mental Health (K99 MH121166). KBS, SMG, JDS, and JS were supported by the University of Washington/Fred Hutch Center for AIDS Research (P30AI027757-32). All authors have read and approved the final version of this paper.

\section{Compliance with Ethical Standards}

Conflict of interest The authors declare that they have no conflict of interest.

\section{References}

1. Holshue ML, DeBolt C, Lindquist S, Lofy KH, Wiesman J, Bruce $\mathrm{H}$, et al. First case of 2019 novel coronavirus in the United States. N Engl J Med. 2020;82(10):929-36.

2. Ortblad KF, Baeten JM, Cherutich P, Wamicwe JN, Wasserheit JN. The arc of HIV epidemics in sub-Saharan Africa: new challenges with concentrating epidemics in the era of 90-90-90. Curr Opin HIV AIDS. 2019;14(5):354-65.

3. Ortblad KF, Salomon JA, Bärnighausen T, Atun R. Stopping tuberculosis: a biosocial model for sustainable development. Lancet. 2015;386(10010):2354-62.

4. UNAIDS. Communities at the centre: defending rights, breaking barriers, reaching people with HIV services. Geneva, Switzerland: UNAIDS; 2019. https://www.unaids.org/sites/default/files/media _asset/2019-global-AIDS-update_en.pdf. Accessed 17 Apr 2020.

5. Dombrowski JC, Ramchandani M, Dhanireddy S, Harrington RD, Moore A, Golden MR. The max clinic: medical care designed to engage the hardest-to-reach persons living with HIV in Seattle and King County Washington. AIDS Patient Care STDs. 2018;32(4):149-56.

6. Dombrowski JC, Galagan SR, Ramchandani M, Dhanireddy S, Harrington RD, Moore A, et al. HIV care for patients with complex needs: a controlled evaluation of a walk-in, incentivized care model. Open Forum Infect Dis. 2019;6(7):ofz294.

7. Gay City: Seattle's LGBTQ Center. About Gay City. https://www. gaycity.org/. Accessed 17 Apr 2020.

8. Stekler JD, McMahan V, Ballinger L, Viquez L, Swanson F, Stockton J, et al. HIV pre-exposure prophylaxis prescribing through telehealth. J Acquir Immune Defic Syndr. 2018;77(5):e40-e4242.

9. McMahan V, McCanta L, Tran D, Herrera L, Viquez L, Swanson $\mathrm{F}$, et al. Insurance and cost-related barriers to PrEP uptake at a safety-net clinic in Seattle, WA. Clin Infect Dis. 2020 (accepted manuscript). https://humaninterests.seattle.gov/2020/05/05/covid -19-and-seattle-human-services-mission Accessed 5 May 2020.

10. Beima-Sofie K, Begnal E, Golden M, Moore A, Ramchandani M, Dombrowski J. "It's me as a person, not me the disease:" patient perceptions of an HIV care model designed to engage persons with complex needs. AIDS Patient Care STDs. 2020 (accepted).

11. Liu S, Yang L, Zhang C, Xiang Y-T, Liu Z, Hu S, et al. Online mental health services in China during the COVID-19 outbreak. Lancet Psychiatry. 2020;7(4):e17-e1818.

12. Kilbourne AM, Justice AC, Rabeneck L, Rodriguez-Barradas M, Weissman S. VACS 3 project team. General medical and psychiatric comorbidity among $\mathrm{HIV}$-infected veterans in the post-HAART era. J Clin Epidemiol. 2001;54(Suppl 1):S22-28.

13. Centers for Disease Control and Prevention. Preexposure prophylaxis for the prevention of HIV infection in the United States-2017 update; a clinical practice guideline. Atlanta, GA: Centers for Disease Control and Prevention; 2017. https://www. cdc.gov/hiv/pdf/prepguidelines2014.pdf. Accessed 7 May 2020.

14. Seattle.gov. COVID-19 \& Seattle Human Services' Mission: To connect people with resources and soluations during times of need. Seattle, WA: Seattle.gov; 2020. https://humaninterests.seatt le.gov/2020/05/05/covid-19-and-seattle-human-services-mission. Accessed 7 May 2020.

Publisher's Note Springer Nature remains neutral with regard to jurisdictional claims in published maps and institutional affiliations. 